\title{
Clinical trial for the control of water intake of patients undergoing hemodialysis treatment*
}

\author{
Graziella Allana Serra Alves de Oliveira Oller \\ Marília Pilotto de Oliveira² \\ Cláudia Bernardi Cesarino \\ Carla Regina de Souza Teixeira ${ }^{2}$ \\ José Abrão Cardeal da Costa ${ }^{4}$ \\ Luciana Kusumota ${ }^{2}$
}

\begin{abstract}
Objective: to analyze the impact of an educational and motivational intervention for patients with a chronic kidney disease, undergoing hemodialysis treatment, on the control of fluid intake during interdialytic periods. Method: a quasi-experimental, non-randomized clinical trial with patients from a Nephrological Unit of the State of São Paulo. Participants were included in two groups: Control Group with 106 patients and Intervention Group with 86 patients, totaling 192 participants. The used intervention was an educational and motivational video to control liquid intake, based on the Bandura's Theory. The measure of control of water intake was the percentage of lost weight, also considered the variable outcome of the research. For the data analysis, descriptive analyses and regression analysis of the Inflated Beta Model were used. Results: patients who participated in the intervention had a decrease in the pattern of weight gain in interdialytic periods, with a 3.54 times more chance of reaching the goal of $100 \%$ of weight loss when compared to participants from the control group. Conclusion: the educational and motivational intervention was effective in reducing the percentage of weight loss in patients undergoing hemodialysis. Brazilian Clinical Trials Registry (ReBEC) under the opinion RBR-4XYTP6.
\end{abstract}

Descriptors: Renal Insufficiency, Chronic; Renal Dialysis; Clinical Trial; Health Education; Weight Gain; Nursing.

\footnotetext{
* Paper extracted from doctoral dissertation "Impact of an educational and motivational intervention for control of water intake in patients under hemodialysis therapy" presented to Escola de Enfermagem de Ribeirão Preto, Universidade de São Paulo, PAHO/WHO Collaborating Centre for Nursing Research Development, Ribeirão Preto, SP, Brazil.

1 Universidade Paulista, São José do Rio Preto, SP, Brazil.

2 Universidade de São Paulo, Escola de Enfermagem de Ribeirão Preto, PAHO/WHO Collaborating Centre for Nursing Research Development, Ribeirão Preto, SP, Brazil.

${ }^{3}$ Faculdade de Medicina de São José do Rio Preto, Departamento de Enfermagem Geral, São José do Rio Preto, SP, Brazil.

${ }^{4}$ Universidade de São Paulo, Faculdade de Medicina de Ribeirão Preto, Ribeirão Preto, SP, Brazil.
}

\section{How to cite this article}

Oller GASAO, Oliveira MP, Cesarino CB, Teixeira CRS, Costa JAC, Kusumota L. Clinical trial for the control of water intake of patients undergoing hemodialysis treatment. Rev. Latino-Am. Enfermagem. 2018;26:e3091.

[Access $\underset{\text { month day }}{\dagger} \underset{\text { year }}{[}$; Available in: DOI: http://dx.doi.org/10.1590/1518-8345.2694.3091. 


\section{Introduction}

Many of the problems experienced by patients with Chronic Kidney Disease (CKD) undergoing hemodialysis treatment are related to a low adherence to the proposed treatment. Fluid overload is common for these patients, and their excess is linked to an increase in the morbidity of this population ${ }^{(1-2)}$.

Although it is regulated by physiological mechanisms, the behavior of fluid intake is also influenced by the person's habits, customs, and social rituals, as well as other factors that trigger water intake, such as a deficit in extracellular volume and blood pressure, and lack of moisture of the oral mucosa and esophagus $^{(3)}$. Thirst plays a role in the maintenance of fluid homeostasis, which implies a network of complex neural and hormonal processes in response to an imbalance in the body's water and sodium ratio(4-5).

Many patients with CKD undergoing hemodialysis treatment intake more fluids than recommended, a practice that is common among these persons ${ }^{(6)}$. The management of liquid intake is a challenge for most patients since, in addition to the liquids, many foods have a high water content, such as fruits, jellies, and soups $^{(7-9)}$. Approximately $95 \%$ of the patients with CKD undergoing hemodialysis do not adhere to the prescribed treatment for water restriction, which can lead to many complications $^{(10)}$.

Patient education is one of the most useful, effective, and accessible health care tools ${ }^{(11)}$. Health behavior change is described as the result of reciprocal relationships between the environment, personal factors, and the attributes of one's behavior(12).

The theory underlying the elaboration of educational material and its implementation in this study was the Cognitive-Social Theory, whose basic principle is the perspective of human agency for self-development, adaptation, and change. Human thought and action are considered as products of a dynamic interrelationship between personal, behavioral, and environmental influences, which enables targeted therapeutic interventions ${ }^{(13)}$.

Several are meanings passing through the imaginary of patients with CKD, from the impact of diagnosis, associated with the recognition of disease severity and treatment, to its consequences, such as the medicinal effects and limits on diet and water habits ${ }^{(14)}$. Changes in living habits because of illness generate difficulties associated with the absence of experiences that provide pleasure, physical incapacity to perform daily activities, travel to dialysis centers, and changes in working and financial conditions. They also refer to concerns about venous access, water control, and dietary restrictions. In general, these situations cause doubts, insecurities, fears, anguishes, and sufferings regarding healing and the possibility of living(15).

Thus, this study aimed to analyze the impact of an educational and motivational intervention for patients with chronic kidney disease undergoing hemodialysis treatment on the control of fluid intake during interdialytic periods.

\section{Method}

A quasi-experimental, non-randomized clinical trial was conducted with patients undergoing hemodialysis treatment at a Nephrology Unit in the State of São Paulo, Brazil. The unit serves 346 patients undergoing hemodialysis treatment, continuous ambulatory peritoneal dialysis (CAPD) and automated dialysis (APD). In the hemodialysis service, patient care is given in shifts, with sessions of four hours each, on Mondays, Wednesdays, and Fridays or on Tuesdays, Thursdays, and Saturdays.

A total of 273 patients were eligible for the study, being divided into two groups: Intervention Group (IG), with 86 patients undergoing hemodialysis on Tuesday, Thursday, and Saturday; and a Control Group (CG), with 106 patients undergoing hemodialysis on Monday, Wednesday, and Friday. This measure was adopted in order to minimize the bias of confusion regarding persons who could meet and exchange information about each other on the intervention. The study design and data collection steps are described in Figure 1.

The following instruments were used for data collection: 1) Instrument for the characterization of socio-demographic, economic, and clinical data; 2) Instrument of General and Perceived Self-efficacy, which is a scale translated and adapted to Brazil in 2004 with the objective of predicting the person's ability to overcome difficulties experienced daily, as well as his/her adaptation after the experience of adverse life events(16); 3) Folkman and Lazarus Coping Strategies Inventory (FLCSI), translated and validated for Brazilian Portuguese in 1995, covering all methodological steps for translation, validation, and cultural adaptation of evaluation instruments. The results of tests indicated that the instrument is accurate and valid for the study of coping strategies and that its application allows identifying ways of dealing with stress ${ }^{(17)}$; 4) Resilience Scale, which was translated, adapted, and validated for Brazil in 2005 and has the objective of measuring the levels of positive psychosocial adaptation in face of important 
life events(18); 5) Hospital Anxiety and Depression Scale (HAD), translated and validated for Brazil in 1995 , this scale aims to detect mild degrees of affective disorders in non-psychiatric settings, in several contexts $^{(19)}$. These instruments were determined as the independent variables of the study.

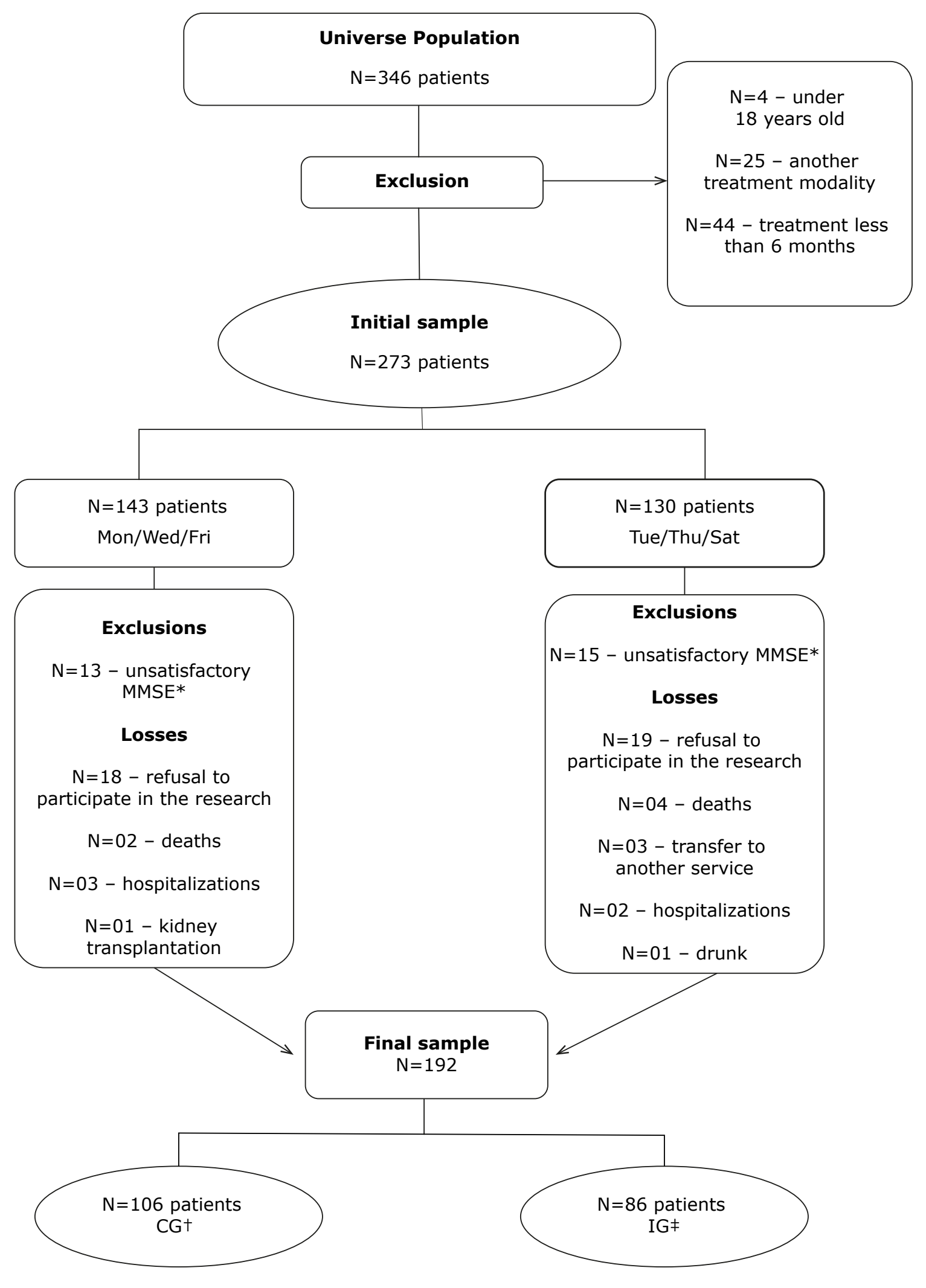

Note: *MMSE - Mini-Mental State Examination; +CG - Control Group; ₹ IG - Intervention Group

Figure 1 - Design of the study participants 
The ideal percentage of weight loss was considered as a variable outcome of the study and was determined by the pre- and post-dialysis weight measurements, as well as the dry weight of each participant, during the study period. Interdialytic weights data collection and follow-up of patients lasted 16 sessions, with preand post-dialysis data recorded by the researcher during the data collection.

A digital media was planned and elaborated in a video format, which was used as educational and motivational strategy, composing the intervention of the study. For the construction of the educational material, a search was made in the scientific literature and in protocols of dialysis service on the topics to be addressed. Thus, an educational video, called "Motivational Intervention - How my kidneys work: treatment and weight gain", was developed based on the Cognitive-Social Theory(13). The following topics were addressed: location and functions of the kidneys; CKD and impairment of kidneys; hemodialysis; guidance on fluid consumption and dialysis complications; measures and care to maintain the hydroelectrolytic balance.

Data collection took place from January to April 2017. The study was conducted over a five-week follow-up period with each patient. The intervention was performed during two meetings, with two more moments for reinforcement with IG patients during hemodialysis, with the stable procedure.

At the first meeting $\left(T_{0}\right)$, the research participants were invited to participate in the research after being informed about it, its relevance, and duration of data collection. At this step, sociodemographic and clinical information were collected, as well as measured the variables of self-efficacy, coping, resilience, and symptoms of anxiety and depression. All CG and IG patients participated in this step.

At the second meeting $\left(T_{1}\right)$, one week after $T_{0}$, the first intervention session was conducted with only the participants of IG. The aim of this step was to provide information on hemodialysis treatment and its complications, demonstrating the effects of excessive water intake in patients with CKD. The educational video was presented in digital format on a tablet. One week later, the first reinforcement $\left(\mathrm{T}_{2}\right)$ occurred, in which a face-to-face approach was taken by the researcher to reinforce the intervention and follow up of the guidelines through feedback. At this step, a dialogued meeting was held between the researcher and the patient in order to verify what the patient in the first intervention has learnt. The patient was encouraged to verbalize the content of the intervention, which led to the realization of complementary guidelines related to possible doubts about the educational and motivational video. This step was performed only with IG participants.

The second session of the intervention occurred one week after the first reinforcement $\left(T_{3}\right)$ to intensify the information on the hemodialysis treatment and its complications and discuss strategies for the reduction of water intake only with IG participants. The researcher gave verbal guidance and presented the educational video again. Strategies for the reduction of water intake were discussed. Three weeks after the first intervention, a new reinforcement $\left(T_{4}\right)$ was performed in a dialogued meeting with the patient to discuss all the issues addressed since the beginning of the study, reinforce, and maintain what was learned.

At the last meeting $\left(T_{5}\right)$, the psychosocial variables of interest (self-efficacy, coping, resilience, and symptoms of anxiety and depression) were measured again by means of an interview with CG and IG patients. The CG patients were submitted to the same measures of the variables of interest in the first and sixth steps and weighed at all intervals as in IG. After completing the data collection, the patients had access to the educational and motivational video.

The data collection of interdialytic weights and patient follow-up lasted 16 sessions ( $P 1$ to $P 16$ ). Interdialytic weight gain was calculated as the difference between the current pre-dialysis weight and the previous post-dialysis weight, i.e. the weight in which the patient started the session to be performed minus the weight at the end of the previous session. Afterward, the measurements were transformed into the "ideal percentage of weight loss", being considered as the variable outcome. Thus, a better visualization on how close to the ideal weight loss the patient reached was obtained. The ideal percentage of weight loss was calculated by the ratio between the actual difference (pre-dialysis weight - post-dialysis weight) and the ideal weight difference (pre-dialysis weight dry weight). The more the patient approaches $100 \%$, the closer he/she is to the ideal weight loss. The measures P4 and P10 corresponded to the stages of implementation of the intervention T1 and T3 of the study. Thus, a better visualization on how close to the ideal weight loss the patient reached was obtained. The steps of data collection are shown in Figure 2. 


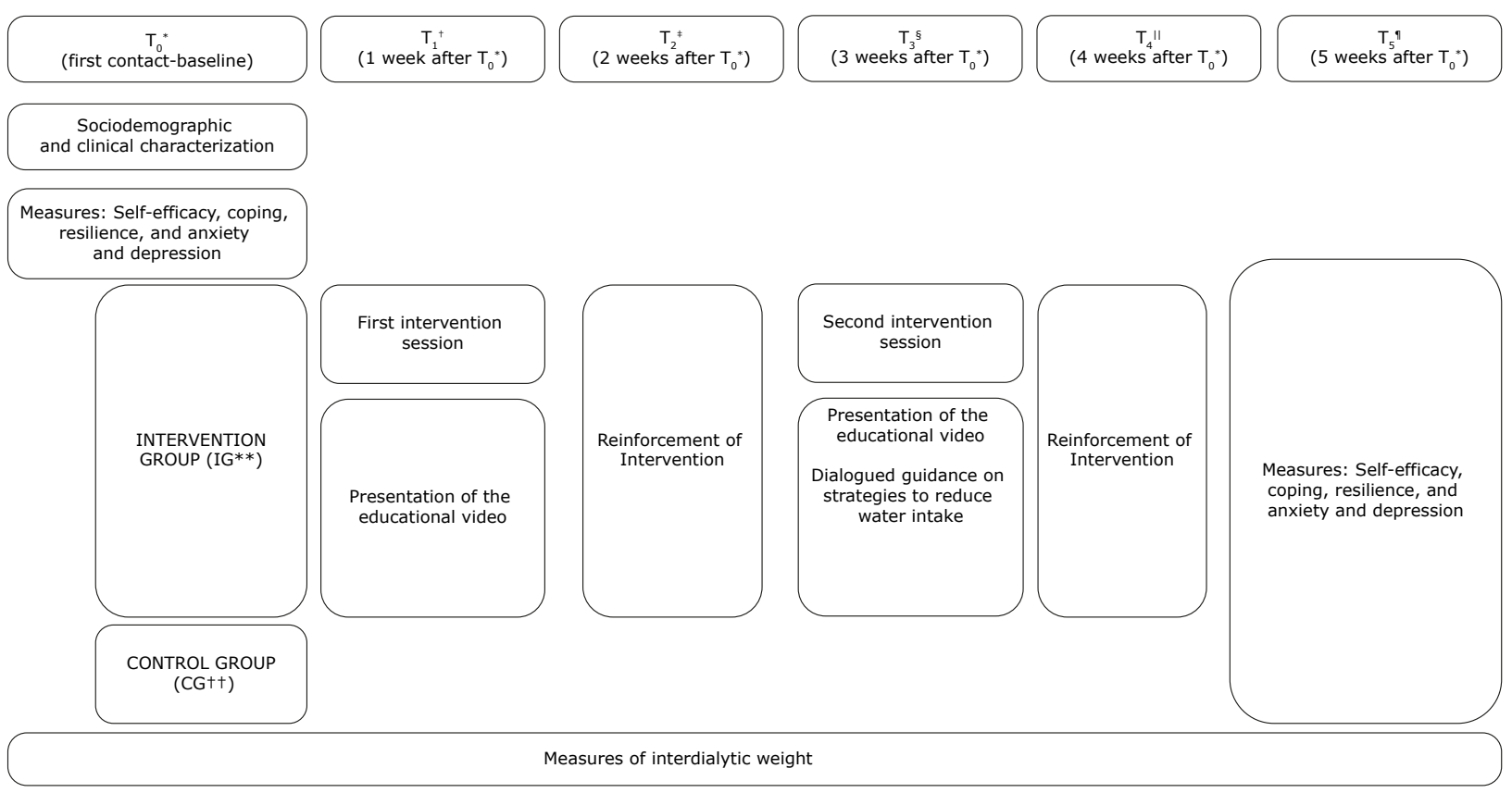

Note: $* \mathrm{~T}_{0}$-baseline; $+\mathrm{T}_{1}$ - one week after $\mathrm{T}_{0} * ; \neq \mathrm{T}_{2}$-two weeks after $\mathrm{T}_{0} * ; \S \mathrm{T}_{3}$-three weeks after $\mathrm{T}_{0} * ; \| \mathrm{T}_{4}$-four weeks after $\mathrm{T}_{0} * ; \boldsymbol{\eta T} \mathrm{T}_{5}$-five weeks after $\mathrm{T}_{0} * ; * * \mathrm{IG}-$ Intervention Group; †+CG-Control Group

Figure 2 - Steps of the study according to the five-week follow-up for data collection and implementation of the intervention

The data analysis was performed using the statistical software SAS 9.0 and the program R version 3.4.1. A descriptive analysis was performed for the categorical variables by means of simple frequency, and the numerical variables were analyzed according to the measures of central tendency and dispersion. For the analysis of the variable outcome, a regression analysis of the Inflated Beta Model was performed ${ }^{(20)}$. The Shapiro-Wilk test was applied to the residuals of the model to verify the hypothesis of their normality.

Confidence intervals with $95 \%$ probability were used and the significance level adopted was $5 \%$.

This research was approved by the Research Ethics Committee of the Ribeirão Preto College of Nursing - EERP/USP, according to Resolution 466/2012 of the National Health Council for research involving human beings under the CAAE: 54339616.6.0000.5393 and Opinion: 1.689.258. Subsequently, the Research Ethics Committee of FAMERP approved the research, where data were collected under the CAAE: 54339616.6.3001.5415 and Opinion: 1.887.840. The research was included in the Brazilian Clinical Trials Registry (ReBEC) under the opinion RBR-4XYTP6.

\section{Results}

A total of 192 patients participated in the study, 106 in GC and 86 in IG. A predominance of male participants was observed in both groups ( $C G=57.6 \%$; IG $=66.3 \%$ ). Age ranged from 18 to 90 years, with an average of
57.6 years in CG and 58.9 years in IG. In relation to the marital status, the participants were predominantly married or living in a consensual union ( $C G=68.9 \%$; IG $=76.7 \%$ ). Regarding schooling, a predominance of patients who could read and write was observed ( $C G=91.5 \%$; IG $=87.2 \%$, with an average of 7.6 years of study in CG and 6.8 years of study in IG. Few patients reported having their own work as income ( $C G=2.8 \%$; IG $=11.6 \%)$. The majority of the participants supported themselves with retirement ( $C G=50.9 \%$; IG $=64 \%$ ).

The self-reported diseases were arterial hypertension (CG $=81.1 \%$; IG $=68.6 \%$ ), visual deficit (CG $=70.8 \%$; IG $=57 \%$ ), diabetes mellitus (CG $=50.9 \%$; IG $=43.0 \%$, among others. The average number of self-reported diseases per patient was 3.4 in CG and 2.9 in IG. Among the physical complications related to $C K D$ and hemodialysis treatment, the most cited by patients were cramps (CG $=83 \%$; IG $=80.2 \%$ ), anemia ( $C G=80.2 \%$; IG $=75.6 \%$ ), and arterial hypotension during the dialysis session ( $C G=79.3 \%$; IG $=73.3 \%$ ). The average number of complications per patient in CG was 6.2 and 7.4 in IG.

Regarding the variable outcome, a tendency to increase the ideal percentage of weight loss during the sessions was observed for all patients, which approached the goal of $100 \%$ lost weight. The variability was lower in IG when compared to CG whereas the ideal percentage of weight loss in patients who reached the goal in IG was higher when compared to CG, except for the initial time (Table 1 ). 
Table 1 - Description of the 16 measures of the variable weight of the 192 patients undergoing hemodialysis treatment according to $\mathrm{CC}^{*}$ and $\mathrm{IG}^{+}$. São José do Rio Preto, SP, Brazil, 2017

\begin{tabular}{|c|c|c|c|c|c|c|c|c|c|c|c|c|}
\hline \multirow[b]{2}{*}{ Time } & \multicolumn{6}{|c|}{$C G^{*}(n=106)$} & \multicolumn{6}{|c|}{$\mathrm{IG}^{\dagger}(\mathrm{n}=86)$} \\
\hline & Minimum & Median & Mean & Maximum & $\mathrm{SD}^{\ddagger}$ & $\begin{array}{c}\text { Ideal } \% \\
\text { of weight } \\
\text { loss }\end{array}$ & Minimum & Median & Mean & Maximum & $\mathrm{SD}^{\ddagger}$ & $\begin{array}{c}\text { Ideal } \% \\
\text { of weight } \\
\text { loss }\end{array}$ \\
\hline $\mathrm{P} 1$ & 29.55 & 100.00 & 94.72 & 100.00 & 10.52 & 0.5849 & 70.69 & 96.92 & 95.18 & 100.00 & 6.26 & 0.4884 \\
\hline $\mathrm{P} 2$ & 50.00 & 100.00 & 95.38 & 100.00 & 8.46 & 0.5755 & 84.21 & 100.00 & 96.76 & 100.00 & 4.60 & 0.5814 \\
\hline P3 & 50.41 & 100.00 & 95.73 & 100.00 & 8.59 & 0.6321 & 83.05 & 100.00 & 97.46 & 100.00 & 4.42 & 0.6744 \\
\hline P4 & 48.76 & 100.00 & 95.62 & 100.00 & 8.68 & 0.6321 & 81.40 & 100.00 & 97.08 & 100.00 & 4.54 & 0.6512 \\
\hline P5 & 49.59 & 100.00 & 96.03 & 100.00 & 8.38 & 0.6604 & 66.67 & 100.00 & 98.97 & 100.00 & 4.32 & 0.9186 \\
\hline P6 & 48.00 & 100.00 & 95.86 & 100.00 & 8.65 & 0.6698 & 71.43 & 100.00 & 99.21 & 100.00 & 3.35 & 0.8721 \\
\hline $\mathrm{P} 7$ & 48.03 & 100.00 & 95.95 & 100.00 & 8.51 & 0.6321 & 70.59 & 100.00 & 98.90 & 100.00 & 3.65 & 0.8372 \\
\hline P8 & 49.59 & 100.00 & 95.19 & 100.00 & 9.31 & 0.6321 & 54.84 & 100.00 & 98.66 & 100.00 & 5.72 & 0.8953 \\
\hline P9 & 47.93 & 100.00 & 95.53 & 100.00 & 9.42 & 0.6698 & 81.25 & 100.00 & 99.28 & 100.00 & 2.49 & 0.8721 \\
\hline P10 & 49.59 & 100.00 & 95.25 & 100.00 & 9.17 & 0.6226 & 54.55 & 100.00 & 98.24 & 100.00 & 5.95 & 0.8140 \\
\hline P11 & 47.58 & 100.00 & 95.19 & 100.00 & 9.12 & 0.5849 & 41.18 & 100.00 & 98.40 & 100.00 & 7.16 & 0.8837 \\
\hline P12 & 50.41 & 100.00 & 95.39 & 100.00 & 9.08 & 0.6415 & 71.43 & 100.00 & 99.45 & 100.00 & 3.18 & 0.9186 \\
\hline P13 & 51.67 & 100.00 & 95.27 & 100.00 & 9.19 & 0.6132 & 78.12 & 100.00 & 99.13 & 100.00 & 3.31 & 0.8953 \\
\hline P14 & 47.50 & 100.00 & 95.54 & 100.00 & 9.11 & 0.6226 & 82.35 & 100.00 & 99.38 & 100.00 & 2.61 & 0.9302 \\
\hline P15 & 47.93 & 100.00 & 95.41 & 100.00 & 9.34 & 0.6226 & 75.00 & 100.00 & 98.95 & 100.00 & 3.74 & 0.8837 \\
\hline P16 & 51.61 & 100.00 & 95.76 & 100.00 & 8.69 & 0.6415 & 87.10 & 100.00 & 99.54 & 100.00 & 2.08 & 0.9302 \\
\hline
\end{tabular}

Note: *CG - Control Group; +IG - Intervention Group; ₹SD - Standard Deviation

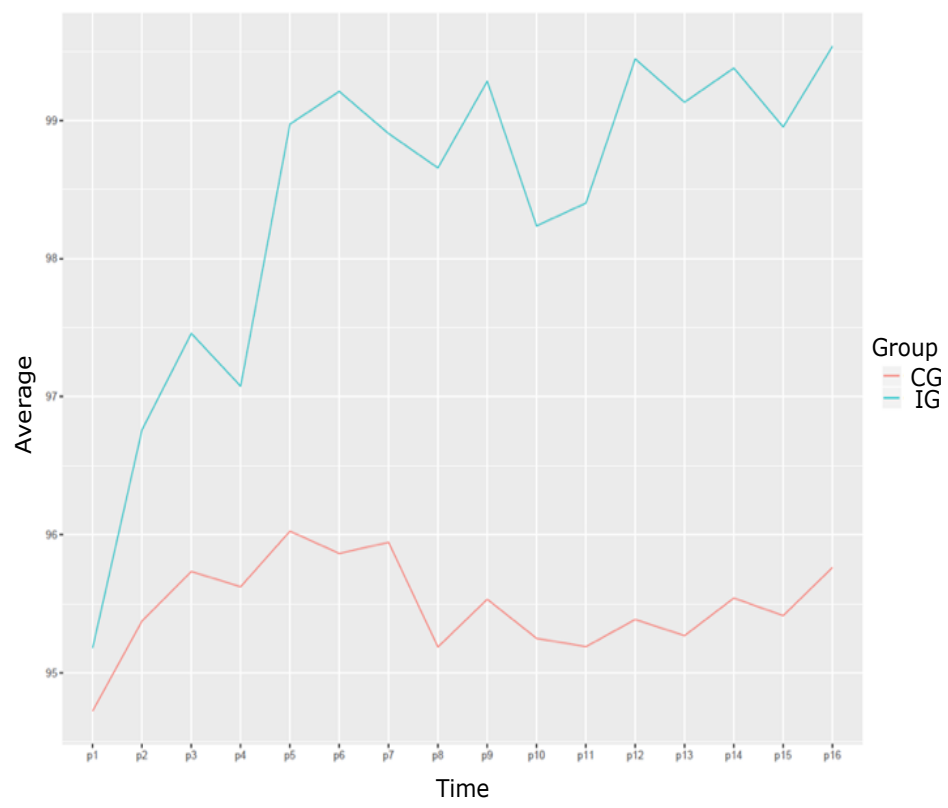

Note: *CG - Control Group; +IG -Intervention Group

Figure 3 - Distribution of the ideal percentage of weight loss by groups (CG* and $\mathrm{IG}^{+}$) over time

Figure 3 shows the progression of the ideal percentage of weight loss in the study period. The increase in the ideal percentage of weight loss stands out in GI, especially from the fifth measurement (P5), which corresponded to the first weight measure after the implementation of the first educational and motivational intervention. In view of these results, it is possible to affirm that the educational and 
motivational intervention had a positive impact on the control of fluid intake, as measured by the ideal percentage of weight loss of patients undergoing hemodialysis treatment.

A regression analysis of the Inflated Beta Model was performed between the outcome and independent variables. In Model 1 of the regression, resulting from the modeling for the parameter $\mu$, the independent variables (groups CG and IG, years of study, time of diagnosis of CKD, time of hemodialysis, number of comorbidities, self-efficacy, the factors confrontation, self-control, social support, escape-avoidance, and positive reevaluation of FLCSI, resilience, depression symptoms, and ideal percentage of weight loss in the 16 times) were related to the outcome, but the model was rejected since the adjustment was not satisfactory for the Shapiro-Wilk test, which indicated rejection of the normality hypothesis for the residuals $(\mathrm{W}=0.9983$, $\mathrm{p}$-value $=0.0020)$.

In Model 2, the independent variables were inserted for dispersion, maintaining all variables of the first step. This modeling for the parameter $\sigma$ was satisfactory for the Shapiro-Wilk normality test and indicated non- rejection of the normality hypothesis for the residuals $(\mathrm{W}=0.9999, \mathrm{p}$-value $=0.3446)$.

However, we proposed the Model 3, choosing to add the modeling to the parameter $\tau$, i.e. the probability of reaching the goal (losing $100 \%$ of the stipulated weight). For this model, the significant variables of $\mu$ and $\sigma$ obtained in Model 2 were maintained. The significant variables for $\tau$ were Group (CG/IG) and the ideal percentage of weight loss in the 16 times, as well as the scores of the scales of resilience, anxiety symptoms, and the factors confrontation, self-control, social support, acceptance of responsibility, and positive reevaluation of FLCSI. All the independent variables inserted in Model 3 showed a statistical significance, except for the variable "weight 2".

For the variable Group (CG/IG), IG participants were 3.54 times more likely to reach the goal when compared to CG. At time 3 of weight measurement, participants were 1.67 times more likely to achieve the goal when compared to time 1 (baseline). The interpretation is analogous to the other times (Table 2).

Table 2 - Regression Analysis of the Inflated Beta Model for the parameter scale, maintaining the significant variables for the mean and dispersion of the 192 patients undergoing hemodialysis treatment. São José do Rio Preto, SP, Brazil, 2017

\begin{tabular}{|c|c|c|c|c|c|c|}
\hline Scale Parameters $\left(\tau^{*}\right)$ & Estimate & $\begin{array}{l}\text { Standard } \\
\text { error }\end{array}$ & p-value ${ }^{\ddagger}$ & $\tau^{*}$ & \multicolumn{2}{|c|}{$95 \% \S \mathrm{Cl} \tau^{*}$} \\
\hline (Intercept) & -1.6424 & 0.4419 & 0.0002 & 0.1935 & 0.0814 & 0.4601 \\
\hline Weight 2 & 0.1666 & 0.2183 & 0.4454 & 1.1813 & 0.7701 & 1.8119 \\
\hline Weight 3 & 0.5125 & 0.2220 & 0.0210 & 1.6695 & 1.0805 & 2.5796 \\
\hline Weight 4 & 0.4616 & 0.2213 & 0.0371 & 1.5866 & 1.0283 & 2.4481 \\
\hline Weight 5 & 1.1975 & 0.2379 & 0.0000 & 3.3118 & 2.0776 & 5.2791 \\
\hline Weight 6 & 1.1013 & 0.2349 & 0.0000 & 3.0081 & 1.8983 & 4.7669 \\
\hline Weight 7 & 0.8912 & 0.2292 & 0.0001 & 2.4380 & 1.5556 & 3.8209 \\
\hline Weight 8 & 1.0394 & 0.2331 & 0.0000 & 2.8275 & 1.7906 & 4.4650 \\
\hline Weight 9 & 1.1013 & 0.2349 & 0.0000 & 3.0081 & 1.8983 & 4.7669 \\
\hline Weight 10 & 0.8061 & 0.2273 & 0.0004 & 2.2391 & 1.4341 & 3.4958 \\
\hline Weight 11 & 0.8625 & 0.2286 & 0.0002 & 2.3691 & 1.5136 & 3.7080 \\
\hline Weight 12 & 1.1329 & 0.2358 & 0.0000 & 3.1047 & 1.9555 & 4.9291 \\
\hline Weight 13 & 0.9791 & 0.2315 & 0.0000 & 2.6620 & 1.6912 & 4.1900 \\
\hline Weight 14 & 1.1013 & 0.2349 & 0.0000 & 3.0081 & 1.8983 & 4.7669 \\
\hline Weight 15 & 0.9791 & 0.2315 & 0.0000 & 2.6620 & 1.6912 & 4.1900 \\
\hline Weight 16 & 1.1650 & 0.2368 & 0.0000 & 3.2058 & 2.0153 & 5.0997 \\
\hline Group IG" & 1.2642 & 0.1097 & 0.0000 & 3.5404 & 2.8555 & 4.3895 \\
\hline Self-efficacy & -0.0369 & 0.0078 & 0.0000 & 0.9638 & 0.9492 & 0.9787 \\
\hline Confrontation Factor (FLCSIף) & 0.7270 & 0.0830 & 0.0000 & 2.0689 & 1.7582 & 2.4345 \\
\hline Escape-Avoidance Factor (FLCSI») & -0.1924 & 0.0609 & 0.0016 & 0.8250 & 0.7321 & 0.9296 \\
\hline Problem solving factor (FLCSI") & 0.2868 & 0.0855 & 0.0008 & 1.3322 & 1.1265 & 1.5753 \\
\hline Positive Reevaluation Factor (FLCSI^) & -0.3789 & 0.1078 & 0.0004 & 0.6846 & 0.5542 & 0.8457 \\
\hline Resilience & 0.0200 & 0.0032 & 0.0000 & 1.0203 & 1.0138 & 1.0267 \\
\hline Symptoms of Anxiety & -0.0399 & 0.0168 & 0.0179 & 0.9609 & 0.9297 & 0.9931 \\
\hline
\end{tabular}

Note: $*_{\tau}$ - Scale parameters, maintaining the significance obtained in mean and scale; $\ddagger \mathrm{p}$-value - Regression Analysis of the Inflated Beta Model; $§ 95 \%$ CI - 95\% confidence interval; ||GI - Intervention Group; ๆFLCSI - Folkman and Lazarus Coping Strategies Inventory 
An increase was observed in the ideal percentage of weight loss of IG patients when compared to CG. Patients with CKD undergoing hemodialysis treatment who participated in the educational and motivational intervention on fluid intake decreased the pattern of weight gain in interdialytic periods.

\section{Discussion}

Education affects the way people behave when facing adversity. Educational practices are effective when they influence the beliefs people have in their own capacities(21). In this study, the positive impact of an educative and motivational intervention elaborated and implemented for the control of fluid intake for patients with CKD undergoing hemodialysis treatment was observed.

The adequate choice of the tool for the development of this educational intervention, coupled with the adoption of a theoretical reference, was essential for conducting the intervention. In this sense, the theoretical reference should allow the favoring of the teaching-learning process.

The intervention used in this study was elaborated according to Bandura's Social Cognitive Theory ${ }^{(13)}$. Patients from IG participated in an educational intervention with the demonstration of a video during the hemodialysis session and dialogues were held to reinforce guidelines on CKD and water intake control.

A study conducted in 2015 aiming at identifying the factors that contribute to the adherence to the diet of patients with CKD undergoing hemodialysis found that $25 \%$ of them did not have adherence to the prescribed treatment and that, in $86 \%$ of cases, it influences the morbidity and mortality of this population. Age, dialysis time, motivation, and distorted perception of adherence to treatment were factors raised as intrinsic barriers to the adherence to diet and water prescription, while self-efficacy, disease perception, and disease control perception were facilitators of the treatment ${ }^{(22)}$.

There are still few studies with a theoretical basis in Bandura with regard to patients with CKD. However, international researches have been increasingly interested in the development and use of interventions to promote and support patients in relation to health care $^{(23-24)}$.

In health settings, patients report thirst as one of the most prevalent and uncomfortable symptoms, which can overcome all other sensations ${ }^{(25)}$. When sodium balance is well controlled, thirst mechanism adequately regulates water balance ${ }^{(26)}$.
Salt intake is a relevant factor in interdialytic weight gain. Patients undergoing hemodialysis treatment receive more fluid in response to the sensation of osmotic thirst, which is usually caused by sodium ingestion(27-28). Immediately after the hemodialysis session, patients may also suffer from volumetric thirst caused by hypovolemia related to the ultrafiltration process $^{(27)}$.

However, during hemodialysis, there may also be a diffuse sodium transfer to the patient. Some authors attribute an increased thirst in patients with CKD undergoing hemodialysis treatment to sodium dialysate prescription. They state that the diffuse sodium transfer to the patient during hemodialysis contributes to the incomplete removal of sodium and that this problem could be minimized with an individualized prescription of sodium dialysate ${ }^{(29-30)}$.

A study carried out with patients undergoing hemodialysis showed that those who underwent hemodialysis sessions with a lower dialytic sodium concentration had a lower interdialytic weight gain and lower blood pressure values. The authors state that changes in sodium dialysate concentration may contribute to a reduction in interdialytic weight gain ${ }^{(31)}$.

Dietary and dialytic sodium restriction may possibly contribute to decreasing volume overload in patients undergoing hemodialysis(32-33). Thus, an adequate sodium balance should compose a goal associated with the control of water intake for these patients.

In addition, a randomized controlled clinical trial conducted in the State of Paraíba, Brazil, with 60 patients with CKD undergoing hemodialysis should be mentioned. The authors evaluated the effect of a musical intervention on anxiety and vital parameters in this population and found a statistically significant reduction of the anxiety score after musical hearing $(p=0.03)$, as well as systolic blood pressure $(p<0.002)$, diastolic blood pressure $(p<0.002)$, heart rate $(p<0.01)$, and respiratory rate $(p<0.006)$. Thus, they demonstrated the musical intervention as a therapeutic resource likely to be used, evidencing the importance of the use of complementary practices by nurses in their daily life ${ }^{(34)}$.

The scarcity of intervention studies with patients with CKD, in particular researches that seeks to investigate water intake control, is evident. Therefore, the educational and motivational intervention used in this study was effective for the control of fluid intake in interdialytic periods of patients with CKD undergoing hemodialysis treatment. In addition, an increase in the ideal percentage of weight loss was observed among the patients who participated in the educational and motivational intervention, being possible to affirm that 
the intervention had a positive impact on the fluid intake control.

As study limitations, there is a non-randomization since patients undergoing hemodialysis perform the treatment on fixed days and times and interact during the sessions, thus establishing contact between IG and CG. If randomized, they could result in biases in outcome evaluations. The financial investment for the production of the educational and motivational video may be another aspect to be considered as limiting to the reproduction of this intervention in some health services. The segment time of the study was considered satisfactory.

\section{Conclusion}

There was a positive impact of the educational and motivational intervention in the control of fluid intake, evaluated through interdialytic weight gain measures of patients with CKD undergoing hemodialysis treatment. An increase in the ideal percentage of weight loss was observed during the sessions, i.e. after the participation in the intervention, the patients had an ideal percentage of weight loss that was closer to that recommended $(100 \%)$. Patients who participated in the intervention had a reduction in the pattern of weight gain in interdialytic periods, with a 3.54 times more chance of reaching the goal of $100 \%$ of weight loss when compared to participants in the control group. There is an increase in the ideal percentage of weight loss of patients of IG when compared to CG.

The educational and motivational intervention was considered positive and adequate to be used in the hemodialysis services since it contributes to the achievement of ideal goals of maintaining the interdialytic weight. Further studies of intervention and use of communication technologies are commendable, and nursing planning can be included in them to subsidize improvements in care delivery.

\section{Referências}

1. Fincham D, Kagee D, Moosa MR. Dietary and fluid adherence among haemodialysis patients attending public sector hospitals in the Western Cape. S Afr J Clin Nutr. [Internet]. 2008 [cited Jun 7 2017];21(2):7-12. Available from: https://www. ajol.info/index.php/sajcn/article/view/34786 doi: 10.1080/16070658.2008.11734155

2. Baraz S, Parvardeh S, Mohammadi E, Broumand B. Dietary and fluid compliance: an educational intervention for patients having haemodialysis. J Adv Nurs. [Internet].
2010 [cited Oct 22 2017];66(1):60-8. Available from: https://www.ncbi.nlm.nih.gov/pubmed/20423436 doi: 10.1111/j.1365-2648.2009.05142.x

3. Leiper J. Thirst. In: Caballero B, Allen L, Prentice A, editors. Encyclopedia of human nutrition. $2^{\text {nd }}$ ed. Oxford: Elsevier/Academic Press; 2005. p. 278-86.

4. Arai SR, Butzlaff A, Stotts NA, Puntillo KA. Quench the thirst: lessons from clinical thirst trials. Biol Res Nurs. [Internet]. 2014 [cited Out. 22 2017] ;16(4):456-66. Available from: doi: 10.1177/1099800413505900

5. Arai S, Stotts N, Puntillo K. Thirst in critically ill patients: from physiology to sensation. Am J Crit Care. [Internet]. 2013 July [cited Oct 23 2017] ;22(4):32835. Available from: doi: 0.4037/ajcc2013533

6. Sinclair $P$, Parker V. Pictures and perspectives: a unique reflection on interdialytic weight gain. HNE Handover: For Nurses Midwives. [Internet]. 2009 [cited Jan 5 2018];36(6):589-96. Available from: http://journals. sfu.ca/hneh/index.php/hneh/article/view/8/6\%20X:/818-1-SM.pdf

7. Welch J, Thomas-Hawkins C. Psycho-educational strategies to promote fluid adherence in adult hemodialysis patients: a review of intervention studies. Int ] Nurs Stud. [Internet]. 2005 [cited Oct 23 2017];42(5):597-608. Available from: https://www. ncbi.nlm.nih.gov/pubmed/15921991 doi: 10.1016/j. ijnurstu.2004.09.015

8. Sarkar S, Kotanko P, Levin N. Fellows' Forum in Dialysis: Interdialytic Weight Gain: Implications in Hemodialysis Patients. Semin Dial. [Internet]. 2006 [cited Oct 23 2017];19(5):429-33. Available from: https://www.ncbi.nlm.nih.gov/pubmed/16970745 doi: 10.1111/j.1525-139X.2006.00199_1.x

9. Sharaf $A$. The impact of educational interventions on hemodialysis patients' adherence to fluid and sodium restrictions. JNHS. [Internet]. 2016 [cited Ago 6 2017];5(3):50-60. Available from: https://pdfs.semanticscholar.org/294a/ d7bcdc4c297ffe397c28b6fa3e348675d47c.pdf doi: 10.9790/7388-0603025060

10. Oshvandi K, Fathabadi MA, Falahi Nia GH, Mahjub $H$, Adib-Hajbaghery M. Effects of small group education on interdialytic weight gain, and blood pressures in hemodialysis' patients. Nurs Midwifery Stud. [Internet]. 2013 [cited Oct 22 2017];1(3):128-32. Available from: doi: $10.5812 / \mathrm{nms} .9910$

11. Dilles A, Heymans V, Martin S, Droogné W, Denhaerynck K, De Geest S. Comparison of a computer assisted learning program to standad education tools in hospitalized heart failure patients. Eur J Cardiovasc Nurs. [Internet]. 2011 [cited Sept 8 2017];10(3):187-93. Available from: doi: 10.1016/j.ejcnurse.2010.07.001 
12. US Department of Health and Human Services. Physical Activity Evaluation Handbook. Atlanta (GA): Centers for Disease Control and Prevention; 2002. [Internet]. 2002 [cited Jan 5 2018]. Available from: https://www.cdc.gov/nccdphp/dnpa/physical/ handbook/pdf/handbook.pdf

13. Bandura A. Self-efficacy: Toward a unifying theory of behavioral change. Psychological Review. [Internet]. 1977 [cited Oct 16 2017]; 84(2):191-215. Available from: http://psycnet.apa.org/record/1977-25733-001

14. Ramos IC, Queiroz MVO, Jorge MSB. Care in situation of severe renal insufficiency: social representations elaborated by adolescentes. Rev Bras Enferm. [Internet]. 2008 [cited Jan 14 2016]:61(2):193-200. Available

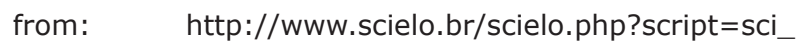
arttext\&pid $=$ S003471672008000200008\&Ing=en

15. Pereira LP, Guedes MVC. Hemodialysis: the renal chronic patient perception. Cogitare Enferm. [Internet]. 2009 [cited Jan 14 2016]:14(4):689-95. Available from: https://revistas.ufpr.br/cogitare/article/ view/16384/10864

16. Souza I, Souza MA. Validation of the General Self-Efficacy Scale. [Internet]. 2004 [cited Jan. 27 2015];26(1-2):12-17. Available from: https://www. researchgate.net/publication/260338439_Validacao_ da_Escala_de_Autoeficacia_Geral_Percebida

17. Savóia MG, Santana P, Mejias NPThe adaptation of Coping Strategies Inventory by Folkman and Lazarus into Portuguese. Psicol USP. [Internet]. 1996 [cited Jan 27 2015];7(1-2):183-201. Available from: http:// http:// pepsic.bvsalud.org/pdf/psicousp/v7n1-2/a09v7n12.pdf 18. Pesce RP, Assis SG, Avanci JQ, Santos NC, Malaquias JV, Carvalhaes R. Cross-cultural adaptation, reability and validity the resilience scale. Cad Saúde Pública. [Internet]. 2005 [cited Jan 27 2015];21(2):436-48. Available from: http://www.scielo.br/pdf/csp/v21n2/10. pdf doi: 10.1590/S0102-311X2005000200010

19. Botega NJ, Bio MR, Zomignani MA, Garcia Jr C, Pereira WAB. Mood disorders among medical in-patients: a validation study of the hospital anxiety and depression scale (HAD). Rev Saúde Pública. [Internet]. 1995 [cited May 16 2015];29(5):355-63. Available from: http:// www.scielo.br/pdf/rsp/v29n5/04.pdf doi: 10.1590/ S0034-89101995000500004

20. Ospina R, Ferrari SLP. Inflated beta distributions. Stat Pap. [Internet]. 2010 [cited Oct 22 2017];51(1):111-26. Available from: https://link. springer.com/article/10.1007\%2Fs00362-008-0125-4 doi: $10.1007 / \mathrm{s} 00362-008-0125-4$

21. Smith BJ, Tang KC, Nutbeam D. WHO health promotion glossary: New terms. Health Promot Int. [Internet]. 2006 [cited Jul 22 2017];21(4):340-5.
Available from: http://www.who.int/healthpromotion/ about/HP\%20Glossay\%20in\%20HPI.pdf doi: 10.1093/ heapro/dal033

22. Orquendo LG, Asencio JMM, Nieves CB. Contributing factors for therapeutic diet adherence in patients receiving haemodialysis treatment: an integrative review. ] Clin Nurs. [Internet]. 2017 [cited Oct 8 2017];26(2324):3893-905. Available from: https://www.ncbi.nlm. nih.gov/pubmed/28295744 doi: 10.1111/jocn.13804 23. Yun KS, Choi JY. Effects of Dietary Program based on Self-efficacy Theory on Dietary Adherence, Physical Indices and Quality of Life for Hemodialysis Patients. J Korean Acad Nurs. [Internet]. 2016 [cited Oct 22 2017];46(4):598-609. Available from: https://www. ncbi.nlm.nih.gov/pubmed/27615049 doi: 10.4040/ jkan.2016.46.4.598

24. Joboshi H, Oka M. Effectiveness of an educational intervention (the Encourage Autonomous SelfEnrichment Program) in patients with chronic kidney disease: a randomized controlled trial. Int J Nurs Stud. [Internet]. 2017 [cited Oct 23 2017];67:51-8. Available from: https://www.ncbi.nlm.nih.gov/pubmed/27918931 doi: $10.1016 / j$.ijnurstu.2016.11.008

25. Conchon MF, Nascimento LA, Fonseca LF, Aroni P. Perioperative thirst: an analysis from the perspective of the Symptom Management Theory. Rev Esc Enferm USP. [Internet].2015 [citedAgo 82017];49(1):120-8. Available from: $\quad$ http://www.scielo.br/scielo.php?script=sci_ arttext\&pid=S0080-62342015000100122 doi: 10.1590/ S0080-623420150000100016

26. Guimarães HCQCP, Barros ALBL. Fluid management: a nursing intervention for the patient with fluid volume excess. Rev. Latino-Am. Enfermagem. [Internet]. 2003 [cited Sept 8 2017];11(6):734-41. Available from: https://www.ncbi.nlm.nih.gov/pubmed/15042199 doi: 10.1590/S0104-11692003000600006

27. Lindley EJ. Reducing sodium intake in hemodialysis patients. Semin Dial. [Internet]. 2009 [cited Jul 15 2017];22(3):260-3. Available from: https://www.ncbi.nlm.nih.gov/pubmed/19573006 doi: 10.1111/j.1525-139X.2009.00570.x

28. Fouque $D$, Vennegoor $M$, ter Wee $P$, Wanner $C$, Basci A, Canaud B, et al. EBPG guideline on nutrition. Nephrol Dial Transplant. [Internet]. 2007 [cited Mar 3 2017];22(Suppl 2):ii45-87. Available from: https://www.ncbi.nlm.nih.gov/pubmed/17507426 doi: $10.1093 / \mathrm{ndt} / \mathrm{gfm} 020$

29. Van der Sande FM, Kooman JP, Leunissen KM. Intradialytic hypotension-new concepts on na old problem. Nephrol Dial Transplant. [Internet]. 2000 [cited Mar 3 2017];15(11):1746-8. Available from: https:// 
www.ncbi.nlm.nih.gov/pubmed/11071958 doi: 10.1093/

ndt/15.11.1746

30. Thijssen S, Raimann JG, Usvyat LA, Levin NW, Kotanko

P. The evils of intradialytic sodium loading. Contrib Nephrol. [Internet]. 2011 [cited Mar 3 2017];171:8491. Available from: https://www.ncbi.nlm.nih.gov/ pubmed/21625095 doi: 10.1159/000327333

31. Munoz Mendoza J, Bayes LY, Sun S, Doss S, Schiller

B. Effect of lowering dialysate sodium concentration on interdialytic weight gani and blood pressure in patients undergoing thrice-weekly in-center nocturnal hemodialysis: a quality improvement study. Am J Kidney Dis. [Internet]. 2011 [cited May 6 2017];58(6):95663. Available from: https://www.ncbi.nlm.nih.gov/ pubmed/21875769 doi: 10.1053/j.ajkd.2011.06.030

32. Kooman JP, van der Sande F, Leunissen K, Locatelli F. Sodium balance in hemodialysis therapy. Semin Dial. [Internet]. 2003 [cited Ago 6 2017];16(5):351-5. Available from: https://www.ncbi. nlm.nih.gov/pubmed/12969379 doi: 10.1046/j.1525139X.2003.16070.x

33. Hecking M, Karaboyas A, Saran R, Sen A, Inaba M, Rayner $\mathrm{H}$,et al. Dialysate sodium concentration and the association with interdialytic weight gain, hospitalization, and motality. Clin J Am Soc Nephrol. [Internet]. 2012 [cited Oct 22 2017];7(1):92-100. Available from: https://www.ncbi.nlm.nih.gov/pubmed/22052942 doi: 10.2215/CJN.05440611

34. Melo GAA, Rodrigues AB, Firmeza MA, Grangeiro AS, Oliveira PP, Caetano JA. Musical Intervention on anxiety and vital parameters of chronic renal patients: a randomized clinical trial. Rev. Latino-Am. Enfermagem. [Internet]. 2018 [cited Aug 8 2018];26:e2978. Available from: http://www.scielo.br/pdf/rlae/v26/ pt_0104-1169-rlae-26-e2978.pdf. DOI: https://dx.doi. org/10.1590/1518-8345.2123.2978 Creative Commons (CC BY).

This license lets others distribute, remix, tweak, and build upon your work, even commercially, as long as they credit you for the original creation. This is the most accommodating of licenses offered. Recommended for maximum dissemination and use of licensed materials. 